\title{
A Study of the In-Column Detection Performance for
}

\section{Chromatography Separation}

\author{
Pei Ling Leow ${ }^{a}$, Pei Song Chee ${ }^{\mathrm{a}}, \cdot$ Bhavik Anil Patel $^{\mathrm{c}}$ and Danny O'Hare ${ }^{\mathrm{b}}$ \\ ${ }^{a}$ Faculty of Electrical Engineering, Universiti Teknologi Malaysia, 81310 Skudai, Malaysia \\ ${ }^{\mathrm{b}}$ Department of Bioengineering, Imperial College, Prince Consort Road, London, SW7 2BY \\ ${ }^{c}$ School of Pharmacy and Biomolecular Sciences, University of Brighton, Huxley Building, \\ Brighton, BN2 4GJ
}

\author{
*Author to whom correspondence should be addressed \\ Tel.: +607-5557170 / ext. 57170 \\ Fax: +607-5566272 \\ E-Mail: leowpl@utm.my
}

\begin{abstract}
This paper studies the in-column detection performance for chromatography separation. Numerical modelling was performed to investigate the detection efficiency of the electrodes that are suspended within a packed chromatography column. The results show that the density of the silica beads packed within the channel does not hinder the detection ability of the electrode. The findings have been further validated with experimental works. A 8 in-column electrode array provides the full separation progress traces of the five neurotransmitters and metabolites (adrenalin, dopamine, DOPAC, serotonin and 5-HIAA) within the column. From the in-column detection, better peak resolutions are developed though the separation column as compared to the conventional post column detection. The whole progress of the separation shows that good separation (Rs > 1) can be obtained at E5 (28.7 $\mathrm{mm}$ from column inlet), whereas baseline separation could be obtained at E8 (last in-column electrode) with Rs $\geq 1.5$ within 60 minutes. The presented results suggest the packing materials within the column does not obstruct the efficiency of the electrodes but able to produce a good baseline separation detection as compared to conventional post column detection.
\end{abstract}

Keywords: Liquid chromatography, Peak resolution, Separation process • In-column detection

\section{Introduction}

Microfluidic device or lab-on-a-chip (LOC) has provided a new era for chemical analysis (Elvira et al. 2013; Livak-Dahl et al. 2011) and offered great benefits for medical diagnosis (Rivet et al. 2011; Jiang et al. 2011). Since early of the 90s, LOC has shown advantages that include reduction of reagents consumption, reduced in 
instrumentation storage space and promised high throughput (Mark et al. 2010). To date, LOC has shown great diversity of functions and applications such as micropump (Chee et al. 2013), capillary electrophoresis (Huang et al. 2008), liquid and gas chromatography (Pruim et al. 2012; Zhu et al. 2012; Luong et al. 2013), micromixer (Tofteberg et al. 2010; Ait Mouheb et al. 2011), and microreactor (Pohar et al. 2012; Hardt et al. 2005) and many more.

In 1979, Terry et al. has first reported a fabricated gas chromatography analyzer on silicon wafer (Terry et al. 1979). Since then, the idea of shrinking the liquid chromatography (LC) system for analytical purposes has been rapidly studied (Lazar et al. 2006). One of the benefits to shrink the size of the LC is to speed up the separation process. However, by integrating the LC onto microfluidics platform has opened up the opportunity for whole column detection (Wang et al. 2010; Chan et al. 2014; Al Lawati et al. 2014). Since the late 1980s, many reports shown great interest in whole column detection for LC as to help better understanding of the separation process within the stainless steel column (Gelderloos et al. 1986; Rowlen et al. 1989; Wu et al. 2005). Besides that, whole column detections provide more than one result per assay as compared to the conventional post column detection. Various whole column detections have been reported, such as using spectroscopic detection which was utilizing optical detectors located externally from the column (Wu and Pawliszyn 2001; Kwok and Manz 2001; van der Sneppen et al. 2007). However, the sensitivity (as respect to Beer-Lambert's Law) of spectroscopic method scales linearly with path length. Voltammetric and amperometric methods present technical challenges but do not suffer for this major disadvantages since they are sensitive to flux, rather than the absolute number of molecules. Alternatively, electrochemical detectors have been shown to be promising but it is technically demanding to decouple the control potential for the sensor (typically <1 V) from the separating voltage $(100-10,000 \mathrm{~V})$ used in capillary electrophoresis separation. Nonetheless, electrochemical approaches are more attractive for miniaturization applications (Fritsch and Aguilar 2007) due to its relative ease of miniaturization, low cost and the exceptional limits of detection $\left(\sim 10^{-15} \mathrm{~mol} \mathrm{dm}^{-3}\right)$. This is also true in nano scale biological analysis (Popovtzer et al. 2006).

Miniaturization of LC device with in-column electrochemical detector was proven to be feasible for in-column detection from our previous work (Seo et al. 2009). From the study of the electrodes' sensitivity, the hydrodynamic properties of the mobile phase increased within the packed column. This in turn, dramatically increases the mass transport on the surface of the electrodes. In this paper, the effort has been further extended to investigate the real time performance of the chemical detection within the packed column. Numerical models with the arrangement of the packed silica beads for $35 \%, 45 \%$ and $60 \%$ particles density under different flow rate are presented. This study is to investigate the detection dependency of the in-laid electrode toward the bead packed densities. The separation efficiency of the developed device with 8 in-column electrode array was experimentally characterized for separating five neurotransmitters and metabolites. The peak resolutions of the incolumn detection were compared with conventional post column detection. 


\section{$2 \quad$ Numerical modeling}

Electrochemical detection highly depends on the electrode's surface properties where the reaction occurs. As has been elucidated by (Seo et al. 2009), induced flow within a packed column improves the mass transportation on the electrode surface. In practical application, the packing materials are likely to be spread randomly within the channel and located above the electrode surface. Therefore, numerical models were built using Comsol Multiphysics ${ }^{\circledR}$ to study the patterns of the diffusive flux at different silica beads arrangements. Models with different density of particles were built representing the packing materials randomly arranged across the microchannel with the channel volume of $25 \mu \mathrm{m} \times 10 \mu \mathrm{m} \times 5 \mu \mathrm{m}$. Each of the models was packed with $5 \mu \mathrm{m}$ size silica beads at the packing densities of $35 \%, 45 \%$ and $60 \%$. Due to the random packing processes, voids or narrow paths are often formed between particles. The contacts surface of the silica beads and the electrode are in a tangent point form in the packed model. Figure 1 depicts the meshing geometry model of the packed microchannel.

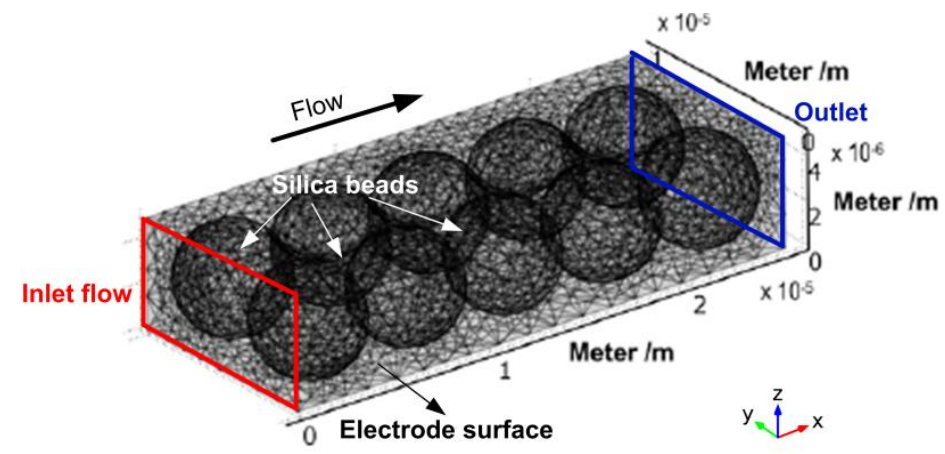

Fig. 1 Numerical model of a packed microchannel

In the numerical model, the bottom layer was set as the electrode surface. The flux density, $J$ which represents the transfer of electron follows Butler-Volmer's formula. These electron travels across the surface as flux where it is proportional to current.

$$
J=F k^{0}\left[C_{O}(0, t) e^{-\alpha f\left(E-E^{0^{\prime}}\right)}-C_{R}(0, t) e^{(1-\alpha) f\left(E-E^{0^{\prime}}\right)}\right]
$$

The $k^{0}$ is the standard rate constant $\left(1 \mathrm{~mm} \cdot \mathrm{s}^{-1}\right), \alpha$ is the transfer coefficient, $f=\mathrm{F} /(\mathrm{R} \cdot \mathrm{T})\left(\mathrm{V}^{-1}\right), E$ and $E^{0^{\prime}}$ are the current and formal potential of an electrode versus a reference respectively, while $C_{O}$ and $C_{R}$ are the concentration of the oxidised and reduced species respectively. For the numerical model, the oxidization of the species is considered and no reduction of the species are considered.

Figure 2 illustrates the bead arrangements of the particles within the microchannels with the packed densities of $35 \%, 45 \%$ and $60 \%$. 


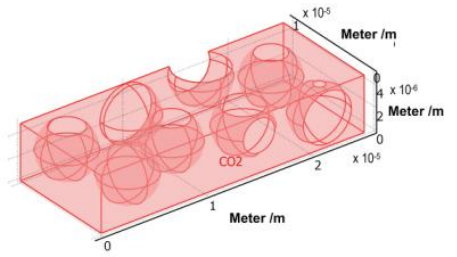

a

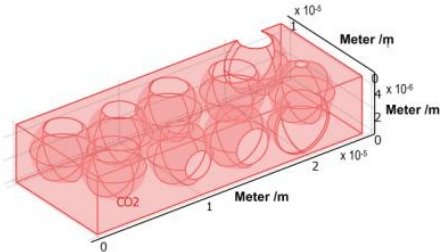

b

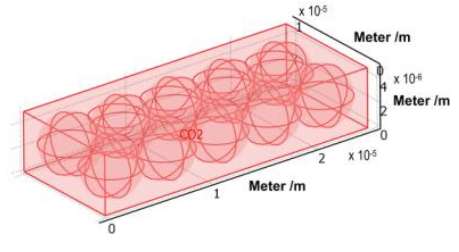

c

Fig. 2 Models of a low density, 35\% b medium density, 45\% and c high density, $60 \%$ of randomly packed sphere particles $(5 \mu \mathrm{m}$ in diameter $)$

The highest density of $60 \%$ was set by assuming that it is impossible to achieve to hexagonal close packed of spherical particles $(74 \%)$ within the channel. The patterns of the normal diffusive flux as regards to the packing density at different applied flow velocity are shown in Fig. 3. The simulated value is further summarised in Table 1.

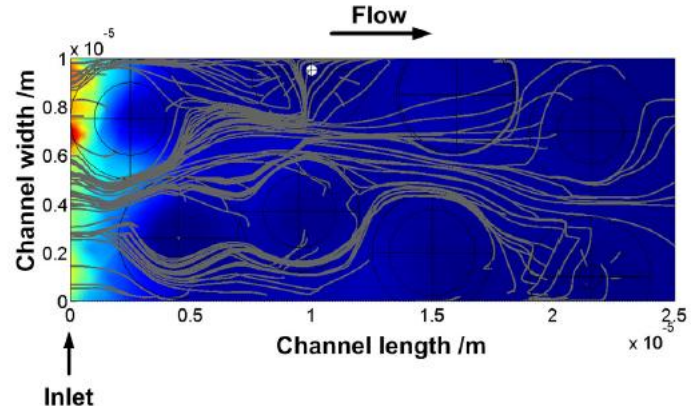

$\mathbf{a}$

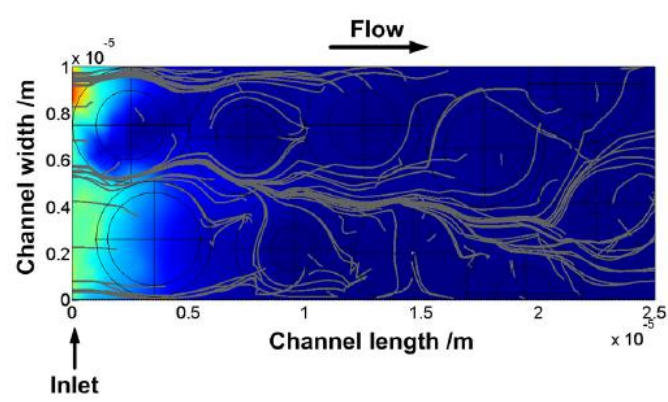

$\mathbf{b}$

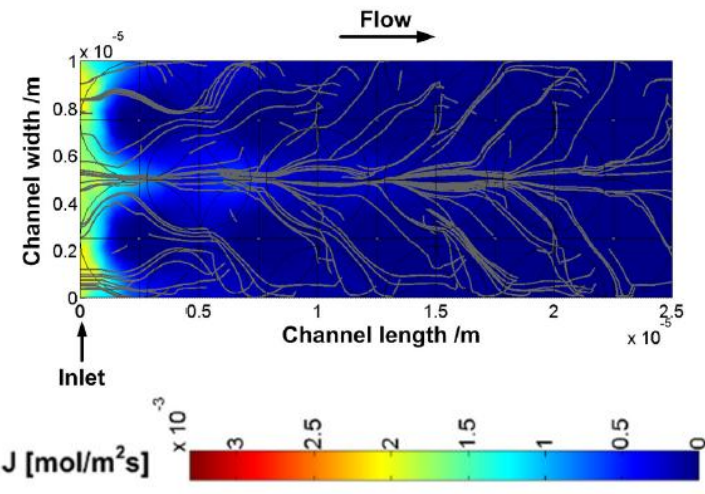

Scale

c

Fig. 3 Top view of the normal diffusion flux distribution on the electrode surface of the electrodes with packing density a low, 35\% b medium, $45 \%$ and $\mathbf{c}$ high $60 \%$ at same flow velocity $1 \mathrm{~mm} \mathrm{~s}^{-1}$ applied at the inlet of the channel. [Grey streamlines indicating the diffusive flux and convection flux in the model.]

Table 1 Normal diffusive flux for three packed models at 35\%, 45\% and 60\% packed density at three different applied flow velocities at the inlet

\begin{tabular}{|c|c|c|c|}
\hline \multirow{2}{*}{$\begin{array}{l}\text { Applied flow } \\
\text { velocity }\left(\mathbf{m m s}^{-\mathbf{1}}\right)\end{array}$} & \multicolumn{3}{|c|}{ Normal diffusive flux $\left(\times \mathbf{1 0}^{-\mathbf{1 4}} \mathbf{~ m o l ~ s}^{\mathbf{- 1}}\right)$ at packing density } \\
\cline { 2 - 4 } & $\mathbf{( 3 5 \% )}$ & $\mathbf{( 4 5 \% )}$ & $\mathbf{( 6 0 \% )}$ \\
\hline $\mathbf{1}$ & 4.954 & 4.836 & 4.516 \\
\hline $\mathbf{2}$ & 7.628 & 6.900 & 7.032 \\
\hline $\mathbf{3}$ & 9.637 & 8.607 & 9.241 \\
\hline
\end{tabular}


From Fig. 3, different streamline patterns of the diffusive flux were observed at different packing density. However, the values of the normal diffusive flux, as depicted in Table 1, do not pose significant trend with the packing density of the column. The applied flow velocity is the dominant factor towards the increased of the diffusive flux. The numerical models show the feasibility of electrochemical detection in packed channels (LC column) at different packed densities despite the blockage reasoned by the spheres particles.

\section{Experimental}

\subsection{Columns}

The experiments were realized by utilizing a homemade LC microfluidic device where the details of the fabrication was reported in (Seo et al. 2009). The microchannel was designed to have the same effective column length of a commercial stainless steel Luna ${ }^{\circledR}$ column (LUNA ${ }^{\circledR}$ ODS $5 \mu \mathrm{m}, 50 \mathrm{~mm} \times 1.0 \mathrm{~mm}$ i.d. analytical column by Phenomenex ${ }^{\circledR}$ ). Figure 4 shows the home made polyethylene terephthalate (PET) microfluidic device.

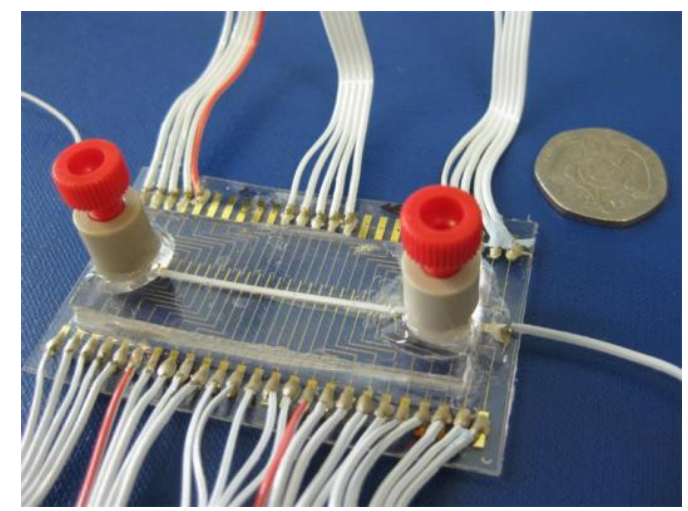

Fig. 4 Home made LC Microfluidic device with 17 gold embedded electrode array

Wires were connected to the connecting pad of the electrode array using conductive silver paste. For storage, the PET column and the commercial stainless steel column were filled up with the mixture of methanol to water solvent (mixing ratio75:25 (v/v)) and sealed with finger tight nuts. The columns were cleaned by deionised water again before flowing through the mobile phase.

\subsection{Experimental setup}

\subsubsection{Chemical}

Five neurotransmitters and metabolites; adrenaline (epinephrine, AD), 3hydroxytyramine (dopamine, DA), 5-hydroxyindole-3-acetic acid (5-HIAA), 3, 4dihydroxyphenylacetic acid (DOPAC) and 5-hydroxytryptamine (serotonin, 5-HT) were obtained from Sigma and used as received. All other chemicals used were 
obtained from VWR International, BDH Prolabo and used as received and stored in fridge at all time. All standards were prepared in class A volumetric glassware.

\subsubsection{Mobile phase}

For the separation of the neurotransmitters, a mobile phase similar to Patel et al. was utilized (Patel et al. 2005). The stock citric acid buffer was prepared as follows: $25 \mathrm{mM}$ sodium dihydrogenorthophosphate, $50 \mathrm{mM}$ sodium citrate, $10 \mathrm{mM}$ of diethylamine, $10 \mathrm{mM}$ sodium chloride and $2 \mathrm{mM}$ of decane-sulfonic acid sodium salt were made up to in $1 \mathrm{~L}$ with deionised, distilled water and buffered to $\mathrm{pH} 3.2$ using concentrated sodium hydroxide. The mobile phase consisted of stock citric acid buffer ( $\mathrm{pH}$ 3.2) mixed with UV- grade methanol (HiPerSolv for HPLC, BDH Prolabo) in a ratio of 97.5: $2.5(\mathrm{v} / \mathrm{v})$ and filtered through a $0.20 \mu \mathrm{m}$ membrane filter and degassed under vacuum after mixing. Samples were freshly prepared using the citric acid buffer and stored in a fridge.

\subsubsection{Instrumentation and chromatography}

The HPLC system consisted of an Agilent HP1050 pump, autosampler and column heater. A single post column detector with $6 \mathrm{~mm}$ radial unijet flow cell glassy carbon electrode (Bioanalytical systems, West Lafayette, IN, USA) and the 17 in-column of microband gold electrode array $(250 \mu \mathrm{m} \times 1 \mathrm{~mm})$ embedded within the PET column were connected to a potentiostat CHI 1030 (CHI Instruments, Inc.). The 17- electrode configuration of the connections to the potentiostat is shown in Fig. 5.

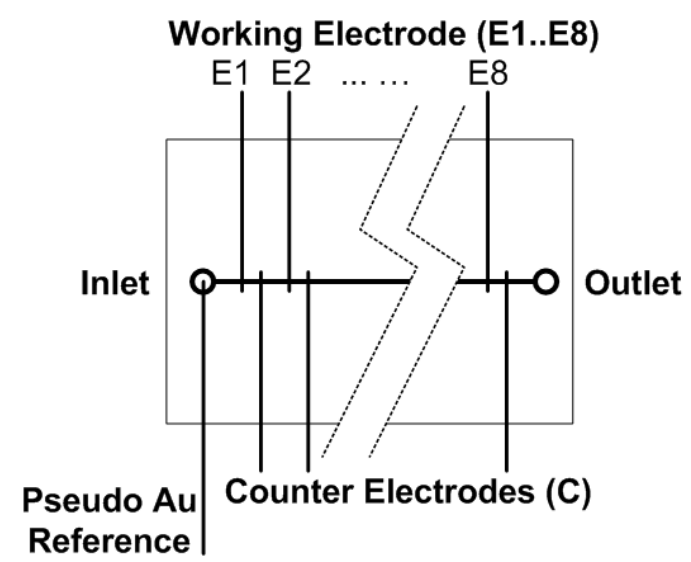

Fig. 5 Electrode configuration used connected to potentiostat CHI 1030

The 17-electrode is forming eight pairing-electrodes and a pseudo gold reference electrode configuration where each working electrode (E1 ... E8) has adjoined to a counter electrode $(\mathrm{C})$. The gap between the working electrode and counter electrode is $1.6 \mathrm{~mm}$ and each pair of electrodes is $4.8 \mathrm{~mm}$ apart from each other. The potential and current for the in-column detectors were controlled by an 8 channel CHI 1030 and set at $+700 \mathrm{mV}$ with respect to gold pseudo reference electrode and gold auxiliary for amperometric technique. The flow rate of mobile phase was set at $80 \mu 1 \mathrm{~min}^{-1}$ for all experiments and the columns' temperature was set to $25 \pm 0.15^{\circ} \mathrm{C}$. 


\section{$4 \quad$ Results and discussion}

A standard mixture of five $2 \mu \mathrm{M}$ neurotransmitters and metabolites (AD, DOPAC, 5-HIAA, DA and 5-HT) were prepared in the mobile phase. A $1 \mu 1$ of this mixture was injected to the column by using the HPLC autosampler. A post-column detector was used to detect the separations of the analytes of both commercial stainless steel column and home-made column. Figure 6 elucidates the chromatograms of the eluted analytes of the two columns.

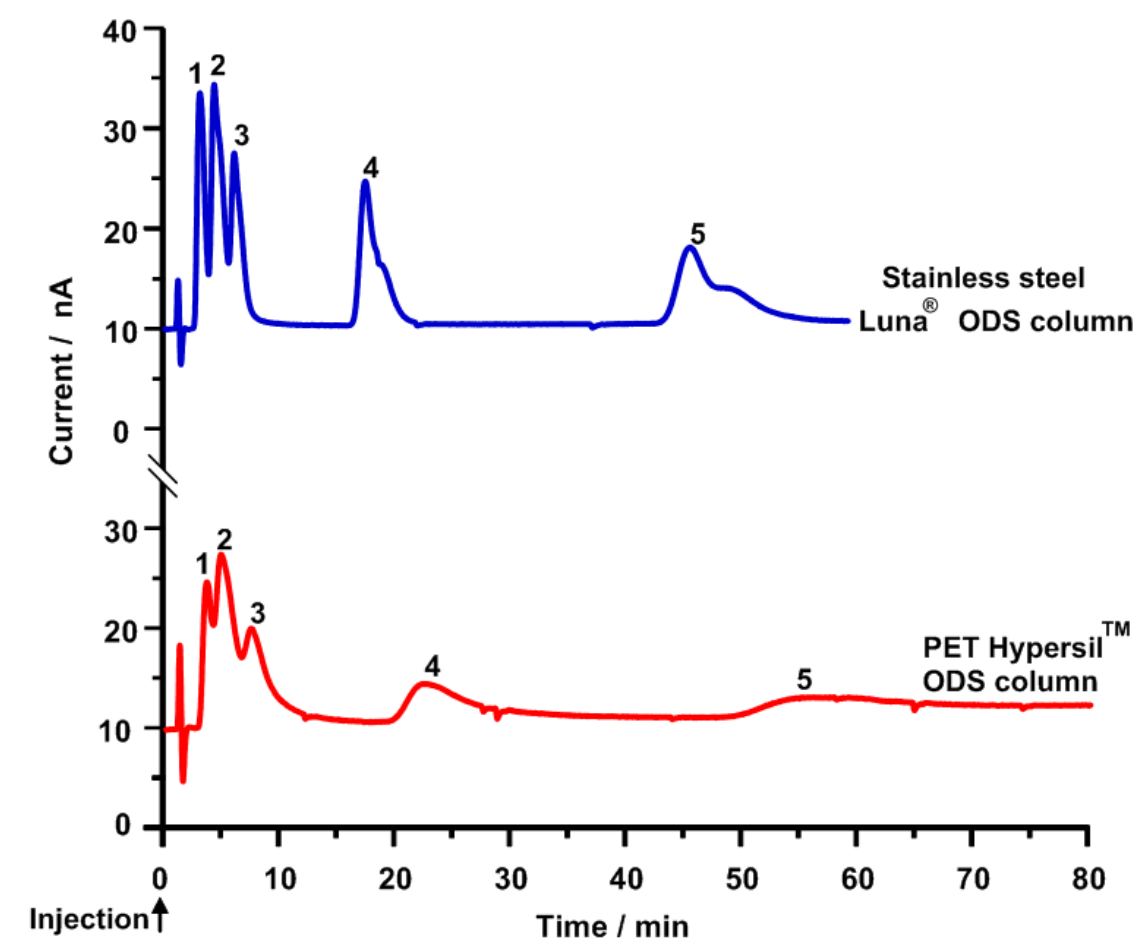

Fig. 6 Post column chromatograms of a standard mixture at $80 \mathrm{ul} \mathrm{min}^{-1}$ using Luna ${ }^{\circledR}$ ODS column and PET HypersilTM ODS column with mobile phase $2.5 \%$ methanol, 97.5\% citric buffer at $25{ }^{\circ} \mathrm{C}$. Solutes: (1) DOPAC; (2) 5-HIAA; (3) adrenaline, AD; (4) DA and (5) serotonin, 5-HT

The developed PET column managed to separate these analytes and showed more retention for all analytes as compared with the commercial column under same mobile phase and flow rate. Band broadening was obvious for the last eluted analyte, serotonin (5-HT) using PET column. The peak resolutions for all analytes using PET column are generally low as compared to the commercial column. As both separation detections were utilizing the same post-column detector, the only reason for the band broadening for PET is the packing quality of the stationary phase within the column. As the PET column was packed using reversed suction method at low pressure, the density of the packing materials within the column is lower as compared to commercial stainless steel column. Hence stainless steel column produces good separation of these analytes.

However, as compared to post column detection, in-column detector shows higher resolutions of the separation. The eight pairing in-column microband electrodes (working - auxiliary) were obtaining simultaneous detection of the separation 
process. $1 \mu \mathrm{l}$ sample mixture consisting of the five analytes (5 $\mu \mathrm{M}$ each), AD, DA, 5HIAA, DOPAC and 5-HT were injected to the LC device via the autosampler. Eight traces of the separation progress within the column is described in Fig. 7 in an isocratic mobile phase with 97.5: $2.5(\mathrm{v} / \mathrm{v})$ buffers to methanol ratio.

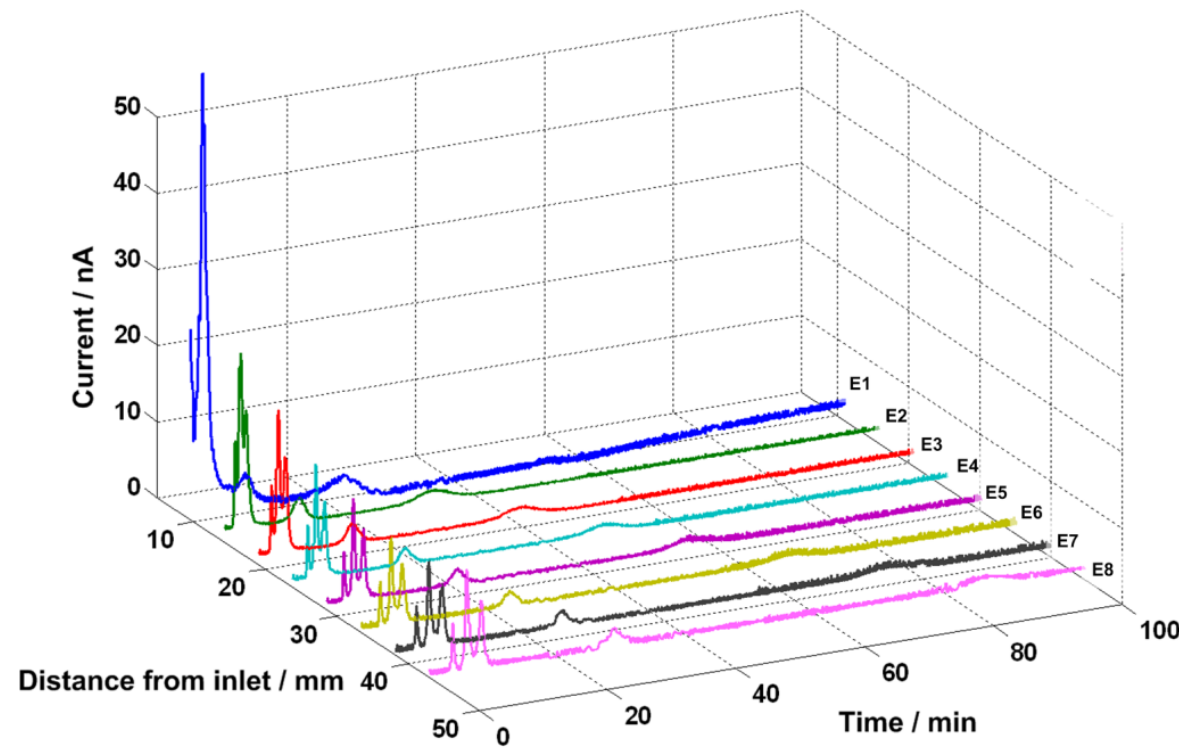

Fig. 7 Full traces of 8 in-column detectors for the separation of five analytes on an isocratic mobile phase in a ratio 97.5:2.5 (v/v) citric buffer: $\mathrm{MeOH}$, analytes eluted in a sequence with first DOPAC, 5-HIAA, AD, DA and finally 5-HT

These in-column electrodes allow real-time separation progress within the column once the sample was injected. As can be observed in Fig.7, electrode 1 (E1) detected three peaks for $1 \mu \mathrm{l}$ of $5 \mu \mathrm{M}$ mixture where the first peak is the mixture of the three analytes: DOPAC, 5-HIAA and AD; the second peak is DA and the third peak is 5HT. The effective column length for E1 was $9.5 \mathrm{~mm}$ from the inlet (include $4.7 \mathrm{~mm}$ from the vertical inlet thickness). From the chromatograms, good separation $\left(R_{s}>1\right)$ of five analytes can be easily observed at E5 ( $28.7 \mathrm{~mm}$ from column inlet) and the whole separation at E5 was completed at 60 minutes. Besides, the separation resolution of all adjoining peaks can be evaluated throughout the whole column to provide a better overview of the separation progress of all analytes. To indicate a baseline separation between two adjacent peaks, the resolutions of five peaks at all electrodes along the column and dotted line $\left(\mathrm{R}_{\mathrm{s}} \geq 1.5\right)$ are plotted in Fig. 8 . 


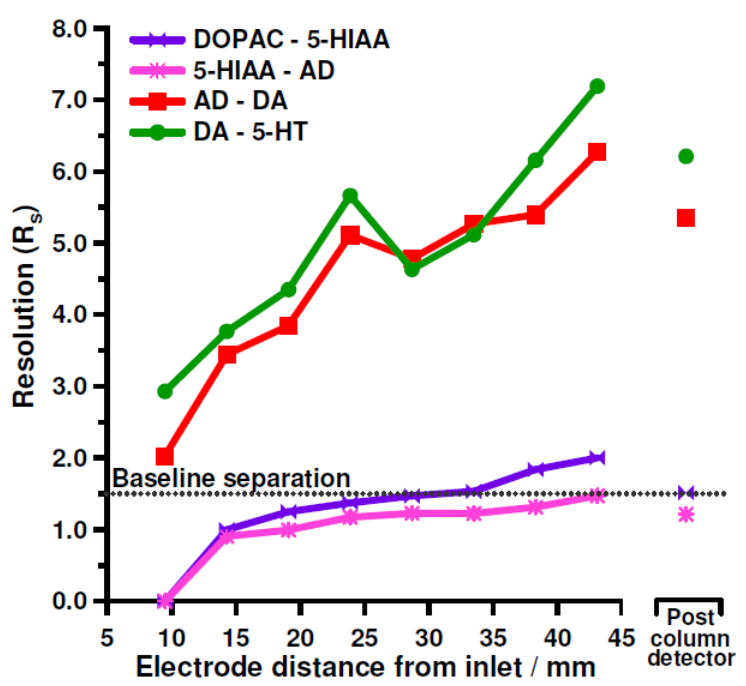

Fig. 8 Separation resolution analysis of five analytes for eight in-column detectors and post-column detector. [Dotted line: Rs $\geq 1.5$ indicates baseline separation.]

The separation resolution of DOPAC, 5-HIAA and AD was low as these three analytes eluted between retention time 2-7 minutes. At the first electrode, no separations happened between these three analytes as the peak resolutions are zero. However, separations between these three analytes improved as the analytes travelled further down the column. At E5 (28.7 mm from column inlet), good separation $\left(\mathrm{R}_{\mathrm{S}}>1\right)$ was obtained with all peaks baseline separated $\left(\mathrm{R}_{\mathrm{S}}>1.5\right)$ except peak 5HIAA and adrenaline $\left(\mathrm{R}_{\mathrm{s}}=1.2\right)$. Dopamine and serotonin were baseline separated since the first in-column electrode and have better resolutions through the separation column.

The in-column detection shows great development of the separation detections as the analytes travelled down the column and the $\mathrm{R}_{\mathrm{s}}$ values for all analytes were decreased at the post-column detection. This may be due to band broadening during the transportation of the eluted solutes from column to the detector. At the last incolumn electrode ( $43.1 \mathrm{~mm}$ from the column inlet) all peaks have baseline separations as $R_{s}$ are at least 1.5. The peak resolutions from the post-column chromatogram, nonetheless, are lower for all peaks. Therefore, the best separation for these five analytes was obtained at the last in-column electrode (E8) yet good separation $\left(R_{s}>1\right)$ has been noticed since E5. This is once again prove that present of the packing materials within the column does not hinder the efficiency of the electrodes but able to produce good baseline separation detection.

\section{Conclusion}

In the present study, the detection performance of an in-column LC device was examined. The arrangement of the packed silica beads was numerically analyzed with finite element approach at the particle densities of 35\%, 45\% and 60\%. The normal diffusive fluxes of the simulated models show that the in-column electrode's detection is independent from the quality of the stationary phase, unlike the post-column detection. A homemade PET based LC device with 17 gold embedded electrode array was experimentally tested to visualize the real-time separation process. The developed in-column detection device shows a good separation of five neurotransmitters and metabolites at $28.7 \mathrm{~mm}$ distance from the column inlet, indicating an improved 
detection resolution as compared to the conventional post-column detection method. In addition, simultaneous detection along the entire length of the separation column is permissible. With this instantaneous whole column detection approach, once the 'fitfor-purpose' data is acquired for experiment, the experiments can be stopped. Future improvements of the in-column approach involve repeatability and robustness studies during chromatography separation process.

Acknowledgements The authors would like to acknowledge Universiti Teknologi Malaysia Research University Grant (Q. J130000.2523.05H29) and Ministry of Education Fundamental Research Scheme (R.J130000.7823.4F462) for funding the research activities.

\section{References}

Ait Mouheb N, Montillet A, Solliec C, Havlica J, Legentilhomme P, Comiti J, Tihon J (2011) Flow characterization in T-shaped and cross-shaped micromixers. Microfluidics and Nanofluidics 10 (6):1185-1197.

Al Lawati HAJ, Kadavilpparampu AM, Suliman FO (2014) Combination of capillary micellar liquid chromatography with on-chip microfluidic chemiluminescence detection for direct analysis of buspirone in human plasma. Talanta 127:230238 .

Chan AS, Danquah MK, Agyei D, Hartley PG, Zhu Y (2014) A Simple Microfluidic Chip Design for Fundamental Bioseparation. Journal of Analytical Methods in Chemistry 2014:6.

Chee PS, Abdul Rahim R, Arsat R, Hashim U, Leow PL (2013) Bidirectional flow micropump based on dynamic rectification. Sensors and Actuators A: Physical 204:107-113.

Elvira KS, i Solvas XC, Wootton RCR, deMello AJ (2013) The past, present and potential for microfluidic reactor technology in chemical synthesis. Nat Chem 5 (11):905-915.

Fritsch I, Aguilar Z (2007) Advantages of downsizing electrochemical detection for DNA assays. Analytical and Bioanalytical Chemistry 387 (1):159-163.

Gelderloos DG, Rowlen KL, Birks JW, Avery JP, Enke CG (1986) Whole column detection chromatography: computer simulations. Analytical Chemistry 58 (4):900-903.

Hardt S, Drese KS, Hessel V, Schönfeld F (2005) Passive micromixers for applications in the microreactor and $\mu$ TAS fields. Microfluidics and Nanofluidics 1 (2):108-118.

Huang W-H, Ai F, Wang Z-L, Cheng J-K (2008) Recent advances in single-cell analysis using capillary electrophoresis and microfluidic devices. Journal of Chromatography B 866 (1-2):104-122. 
Jiang H, Weng X, Li D (2011) Microfluidic whole-blood immunoassays. Microfluidics and Nanofluidics 10 (5):941-964.

Kwok YC, Manz A (2001) Shah convolution differentiation Fourier transform for rear analysis in microchip capillary electrophoresis. Journal of Chromatography A 924 (1-2):177-186.

Lazar IM, Trisiripisal P, Sarvaiya HA (2006) Microfluidic Liquid Chromatography System for Proteomic Applications and Biomarker Screening. Analytical Chemistry 78 (15):5513-5524.

Livak-Dahl E, Sinn I, Burns M (2011) Microfluidic Chemical Analysis Systems. In: Prausnitz JM (ed) Annual Review of Chemical and Biomolecular Engineering, Vol 2, vol 2. Annual Review of Chemical and Biomolecular Engineering. Annual Reviews, Palo Alto, pp 325-353.

Luong J, Gras R, Shellie RA, Cortes HJ (2013) Applications of planar microfluidic devices and gas chromatography for complex problem solving. Journal of Separation Science 36 (1):182-191.

Mark D, Haeberle S, Roth G, von Stetten F, Zengerle R (2010) Microfluidic lab-on-achip platforms: requirements, characteristics and applications. Chemical Society Reviews 39 (3):1153-1182.

Patel BA, Arundell M, Parker KH, Yeoman MS, O'Hare D (2005) Simple and rapid determination of serotonin and catecholamines in biological tissue using highperformance liquid chromatography with electrochemical detection. Journal of Chromatography B 818 (2):269-276.

Pohar A, Lakner M, Plazl I (2012) Parallel flow of immiscible liquids in a microreactor: modeling and experimental study. Microfluidics and Nanofluidics 12 (1-4):307-316.

Popovtzer R, Neufeld T, Ron Ez, Rishpon J, Shacham-Diamand Y (2006) Electrochemical detection of biological reactions using a novel nano-bio-chip array. Sensors and Actuators B: Chemical 119 (2):664-672.

Pruim P, Schoenmakers P, Kok W (2012) Microfluidic Pressure Driven Liquid Chromatography of Biologically Relevant Samples. Chromatographia 75 (2122):1225-1234.

Rivet C, Lee H, Hirsch A, Hamilton S, Lu H (2011) Microfluidics for medical diagnostics and biosensors. Chemical Engineering Science 66 (7):1490-1507.

Rowlen KL, Duell KA, Avery JP, Birks JW (1989) Whole column detection: application to high-performance liquid chromatography. Analytical Chemistry 61 (23):2624-2630.

Seo J-H, Leow PL, Cho S-H, Lim H-W, Kim J-Y, Patel BA, Park J-G, O'Hare D (2009) Development of inlaid electrodes for whole column electrochemical detection in HPLC. Lab on a Chip 9 (15):2238-2244.

Terry SC, Jerman JH, Angell JB (1979) A gas chromatographic air analyzer fabricated on a silicon wafer. Electron Devices, IEEE Transactions on 26 (12):1880-1886. 
Tofteberg T, Skolimowski M, Andreassen E, Geschke O (2010) A novel passive micromixer: lamination in a planar channel system. Microfluidics and Nanofluidics 8 (2):209-215.

van der Sneppen L, Ariese F, Gooijer C, Ubachs W (2007) Cavity ring-down spectroscopy for detection in liquid chromatography at UV wavelengths using standard cuvettes in a normal incidence geometry. Journal of Chromatography A 1148 (2):184-188.

Wang Z, Wang W, Chen G, Wang W, Fu F (2010) Liquid chromatography on a monolithic column microfluidic chip coupled with "three-T" sample injection mode and amperometric detection. Journal of Separation Science 33 (1718):2568-2574.

Wu X-Z, Huang T, Liu Z, Pawliszyn J (2005) Whole-column imaging-detection techniques and their analytical applications. TrAC Trends in Analytical Chemistry 24 (5):369-382.

Wu X-Z, Pawliszyn J (2001) Application of Whole Column Imaging Capillary Isoelectric Focusing in Study of Protein-Protein Interaction. Analytical Sciences - The Japan Society for Analytical Chemistry 17 (SUPPLEMENT):i189 - i192.

Zhu Y, Chen H, Du G-S, Fang Q (2012) Microfluidic droplet-array liquid-liquid chromatography based on droplet trapping technique. Lab on a Chip 12 (21):4350-4354. 